\title{
DETERMINANTS OF UNDER-FIVE MORTALITY IN BUILSA DISTRICT, UPPER EAST REGION, GHANA
}

\author{
K. Osei-Kwakye, ${ }^{1}$ E. Otupiri, ${ }^{2}$ E. Owusu Dabo, ${ }^{2}$ E.N.L. Browne ${ }^{2}$, and M. Adjuik ${ }^{3}$ \\ ${ }^{1}$ Kintampo Health Research Centre, Ghana Health Service, Kintampo, Ghana \\ ${ }^{2}$ Department of Community Health, School of Medical Sciences, College of Health \\ Sciences, Kwame Nkrumah University of Science and Technology, Kumasi \\ ${ }^{3}$ Navrongo Health Research Centre, Ghana Health Service, Navrongo
}

\begin{abstract}
Under-five mortality rate is an important indicator of a community's social development. The Upper East region, one of the most poverty-stricken regions in Ghana, has however recorded a dramatic decline in its under-five mortality rate since 1993; from 180 per 1000 live births to 79 per 1000 live births in 2003. The aim was to identify the determinants of under-five mortality in Builsa district. A case-control study was used to collect data from mothers of 60 cases and 120 controls matched for age, sex and place of residence. Even though $70 \%$ of mothers were illiterate, the educational level of mothers did not influence the child's risk of death (OR 1.1). Children of mothers who had had previous child deaths were about 8 times more likely to die (OR 7.45,) while those who had not had vitamin A supplementation were about 10 times more likely to die (OR 9.57). Over 90\% of mothers had an insecticide-treated bednet and more than 50\% of them exclusively breastfed their children for the first 6 months of life. Protective risk factors identified included: exclusive breastfeeding (OR 0.72), use of an insecticide-treated bednet (OR 0.12), the number of live children a mother had (OR 0.54) and immunization (OR 0.53). Even in poverty, it is possible to improve the child health status of communities. Health staff should be equipped to pay special attention to mothers with previous child deaths in order to assist them to prevent further deaths.
\end{abstract}

Keywords: Under-five mortality, determinants, case-control study, Builsa district

\section{INTRODUCTION}

Under-five mortality rate (U5MR) is the probability that a newborn will die before reaching the age of five years if subjected to current agespecific mortality rates. It is usually expressed as a rate per 1000 live births. Nearly 10 million children worldwide die before their fifth birthday, with almost all of such deaths occurring in developing countries; sub-Saharan Africa
(SSA) alone accounts for almost $50 \%$ of these deaths (Black et al., 2003; Claeson et al., 2003, WHO, 2007; UNICEF, 2008).

Under-five deaths are caused by easily manageable or preventable diseases such as malaria, measles, pneumonia, diarrhoeal diseases (or a combination of such diseases) with malnutrition playing a role in more than half of such deaths (WHO, 2000; Bryce et al., 2003, Bryce 


\section{Osei-Kwakye et al.}

et al., 2005). Though under-five mortality rates have been declining worldwide, developing countries continue to record high values and in low-income countries, one child in 11 dies before his/her fifth birthday in comparison to one in 143 in high-income countries (United Nations, 2000; WHO, 2003).

Certain factors such as socioeconomic status, fertility behaviour, environmental health conditions, nutritional status and infant feeding, and the use of health services have been identified as strong risk factors for child mortality. The magnitude of each factor varies in various regions across the world (Mosley and Chen, 1984).

Ghana was ranked forty-seventh $\left(47^{\text {th }}\right)$ in the world in terms of under-five mortality rate in 2002, with a rate of 100 per 1000 live births (down from 126 per 1000 live births in 1990) and an infant mortality rate (IMR) of 57 per 1000 live births (UNICEF, 2004). However, the rates increased slightly to 111 per 1000 live births and 64 per 1000 live births for under-five and infant mortality respectively for the year 2003 (GSS/NMIMR/ORC Macro, 2004) and in 2008, went down to 80 and 50 per 1000 live births respectively (GSS/GHS//ORC Macro, 2008 preliminary results). To achieve the $4^{\text {th }}$ Millennium Development Goal (MDG), Ghana has to reduce her U5MR rate to 40 per 1000 live births by 2015 (Bryce et al., 2008). The annual rate of U5MR reduction in Ghana (1990 -2006 ) is $0.09 \%$. Between 2007 and 2015, Ghana has to achieve an annual rate of reduction of $12.2 \%$ in order to achieve the MDG 4 (Countdown Coverage Writing Group, 2008).

The Upper East Region of Ghana (in which Builsa District is located), has been classified as one of the worst poverty stricken regions of Ghana with $40 \%$ of its population living in abject poverty and nine out of ten people in the region being said to be poor (Ghana Poverty Reduction Strategy, 2003). In spite of this, the region has recorded a dramatic decline in under -five and infant mortality rates since 1993 (U5MR - 180/1000 and IMR - 105/1000 live births). The 2003 Ghana Demographic and
Health Survey (GDHS) showed a regional U5MR and IMR of 79 per 1000 live births and 33 per 1000 live births respectively which were lower than the national rates; 111 per 1000 live births and 64 per 1000 live births respectively.

The study sought to determine the influence of evidence-based risk factors for under-five mortality on the under-five mortality rate in the district and to describe the factors that may have led to the sharp drop in under the U5MR in the district (and possibly also in the region).

\section{MATERIALS AND METHODS \\ Study Area}

The Builsa District is one of the eight districts in the Upper East region of Ghana. It has six sub-districts. The health infrastructure in the district consists of a district hospital, two (2) mission clinics, four (4) health centres, two community-based health services and planning (CHPS) compounds and eighty-one (81) outreach points. Endemic diseases in the district are: malaria, tuberculosis, leprosy, schistosomiasis, respiratory tract infections, intestinal worms, sexually transmitted infections (STIs) and diarrhoea while the main epidemic-prone diseases are cerebrospinal meningitis (CSM), measles and yellow fever.

Records from the Builsa District Hospital indicate high proportions of deaths in the underfive age group out of all deaths occurring in the hospital. In 2001, 27.8\% of all deaths in the hospital were in children under-five. This increased to $33.2 \%$ in 2002 but decreased slightly to $31.5 \%$ in 2003 (Ghana Health Service/Builsa District Health Management Team, 2004).

\section{Methods}

A comparative study with a case-control design was used. The cases were defined as children below five years who died at the Builsa District hospital or in the communities (as identified from community-based surveillance records), from January 2003 to June 2005. Data on the cases were collected via a review of the district hospital records of deaths among children under-five admitted to the hospital from January 2003 to June 
2005 and also from the sub-district communitybased surveillance (CBS) records as well as through interviews with community-based volunteers to further identify any under-five deaths that may not have been recorded in the CBS records at the time of the study. Informed verbal consent was sought from mothers or guardians of cases before they were interviewed. A total of 74 cases were identified from the Builsa District hospital records for the period January 2003 to June 2005. Of the 74, 38 were eventually recruited to participate in the study; the rest either did not consent to participate or had wrong addresses and could not be traced or were not available at the recorded address at the time of the study or were not residents of Builsa District. An additional 22 cases were captured from the CBS records and from information provided by the community-based volunteers.

Controls for the study were children matched for the same age (range: \pm 2 months of age of a case as at the time of his/her death), sex, who lived in the same communities as cases (or in nearby communities) and who were alive at the time of the study. Mothers and or guardians of controls assisted in the identification of other potential controls. The community-based surveillance volunteer assisted in the location of the house of the potential control. The respective child was selected as a control only after an informed consent had been obtained from the child's parents or guardian(s). A total of 120 controls were recruited.

Ethical clearance for the study was obtained from the KNUST-KATH Committee on Human Re- search, Publications and Ethics (CHRPE), while administrative clearance was obtained from the Builsa District Health Directorate.

\section{STATISTICAL ANALYSIS}

The sample size was calculated as follows: 60 cases and 120 controls based on a $60 \%$ prevalence of infectious diseases among under-fives in the district for the control group with 3 as the odds ratio worth detecting at a $95 \%$ confidence level with a power of $80 \%$ and allowing for a $10 \%$ non-response rate (Epitable Calculator, Epi Info $^{\mathrm{TM}}$ 6.04d (CDC, Atlanta).

Data were analyzed using Epi Info 2000 (C) CDC, USA; WHO, Geneva) and Stata 8 for Windows (C) College Station, Texas 77845 USA). Summary statistics for the variables were determined. For categorical variables, frequencies and sometimes cross-tabulations were used to describe the relationships between study variables. The chi-square test statistic was used to determine the statistical significance of associations between variables. Continuous variables were summarized using the mean with a $95 \%$ confidence interval as measure of dispersion. For skewed variables, the median and the inter-quartile range were used to report the summary. Bi-variate conditional logistic regression was used to identify the variables that were likely to be risk factors for under-five mortality. Odd ratios were reported together with $95 \%$ confidence intervals. The critical level of significance was $p \leq 0.05$.

Table 1: Distribution of cases and controls by age and sex

\begin{tabular}{lccccc}
\hline \multirow{2}{*}{$\begin{array}{l}\text { Age Group } \\
\text { (months) }\end{array}$} & $\begin{array}{c}\text { Males } \\
\text { n (\%) }\end{array}$ & $\begin{array}{c}\text { Females } \\
\text { n (\%) }\end{array}$ & $\begin{array}{c}\text { Males } \\
\text { n (\%) }\end{array}$ & $\begin{array}{c}\text { Females } \\
\text { n (\%) }\end{array}$ & $\begin{array}{c}\text { Total } \\
\text { N (\%) }\end{array}$ \\
\hline $\mathbf{0 - 1 1}$ & 22 & 16 & 44 & 34 & 116 \\
& $(61 \%)$ & $(67 \%)$ & $(61 \%)$ & $(71 \%)$ & $(64 \%)$ \\
$\mathbf{1 2 - 5 9}$ & 14 & 8 & 28 & 14 & 64 \\
& $(39 \%)$ & $(33 \%)$ & $(39 \%)$ & $(29 \%)$ & $(36 \%)$ \\
Total & 36 & 24 & 72 & 48 & 180 \\
\hline
\end{tabular}

The \% have been rounded off to the nearest whole number 


\section{RESULTS}

Majority of the mothers in both study groups were illiterate $(\sim 70 \%)$ and were also farmers. Most mothers were assessed to be in the middle level with regard to economic status (assessed based on the possession of assets such as radio, bicycle and the quality of building materials for their houses among others).

There were almost twice as many infants (0-11 months) as there were young children (12-59 months) in the study population; $64 \%$ to $36 \%$ respectively. Nearly two-out-of three deaths $(60 \%)$ were males. Most of the deaths (63\%) occurred among infants, with 22 (37\%) dying before they were six months old.

The major causes of morbidity among children under-five in Builsa District were: malaria, diarrhoea, acute respiratory infections (ARI) notably pneumonia, and anaemia (Table 2).

Figure 1 shows the causes of under-five deaths at Builsa District Hospital from January 2003 to June 2005. The same diseases also account for the major causes of mortality among children in the district..
Table 2: Top-5 causes of severe morbidity ${ }^{1}$ in children under-five in Builsa District Hospital, Ghana: 2004

\begin{tabular}{lcc}
\hline Condition & Number & $\begin{array}{c}\text { \% of Total } \\
\text { Admissions }\end{array}$ \\
\hline 1. Malaria & 940 & 23.0 \\
4. Diarrhoea & 442 & 10.8 \\
2. ARI & 267 & 6.5 \\
3. Anaemia & 234 & 5.7 \\
5. UTI & 64 & 1.6 \\
\hline
\end{tabular}

('severe morbidity is defined as illness episode that led to admission)

${ }^{2}$ Urinary tract infection

Source: Builsa DHMT, Annual Performance Review, 2004

\section{Known risk factors for under-five mortality Socio-economic factors \\ Socio-economic factors such as: religion, mother's educational level and mother's in- come level, did not have any influence on un- der-five mortality in the district.}

\section{Maternal factors}

Maternal age at childbirth was not identified as a significant factor for under-5 mortality (OR

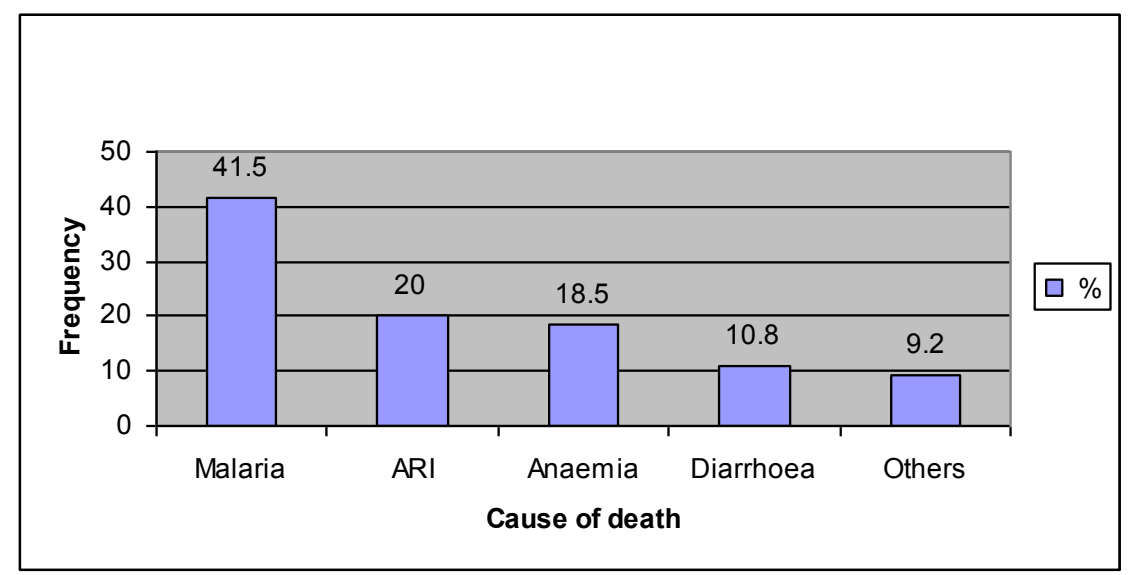

Fig. 1: Causes of under-five mortality in Builsa District Hospital, Ghana; January 2003 to June 2005

Source: Builsa DHMT Reports, 2003 - mid 2005 
$0.97,95 \%$ CI [0.91- 1.05], $\mathrm{p}=0.52$ ). Other maternal factors such as: antenatal clinic (ANC) attendance, parity and mother's occupation did not significantly influence under-five mortality. However, the more children a mother had alive, the lower the risk of death (OR 0.54, 95\% CI [0.40-0.73] $\mathrm{p}<0.01)$ for these children. Children of mothers who had had one or more dead children were about eight (8) times at risk of death (OR 7.45, 95\% CI [3.63-15.47], $\mathrm{p}<0.01$ ).

\section{Hygiene}

Mothers were asked whether they washed their hands with soap (and how often) in the following instances: before preparing food for their children, before breastfeeding them, after visiting the toilet, after disposing of their children's faeces and before or after any other activities. Nearly half of mothers in both groups; $30(50.8 \%)$ cases $[\mathrm{N}=59]$ and $60(51.2 \%)[\mathrm{N}=117]$ controls respectively, said they always washed their hands in all the above-mentioned instances (but not before breastfeeding). Hygiene was not a significant factor in under-five mortality in the district.

\section{Nutrition}

More than half of the women in both study groups; 31(53.4\%) [N=58] cases and 87(75.7\%) $[\mathrm{N}=115]$ controls, practiced exclusive breastfeeding for the recommended period of the first six months of life. The majority of women in both groups; 50(86.2\%) $[\mathrm{N}=58]$ cases and $104(88.9 \%)$ $[\mathrm{N}=117]$ controls put their babies to the breast within one hour of birth. The practice of exclusive breastfeeding was also found to be a protective factor in relation to under-five mortality in the district (OR 0.72, 95\% CI [0.56-0.92], $\mathrm{p}=0.01$ ).

One of the questions the study wanted to answer was how many children in both groups had received vitamin $\mathrm{A}$ in the six months prior to the interview (for controls) or six months prior to the death of a case. Among the cases, 42(72.4\%) received vitamin A while 16(27.6\%) [N=58] did not receive vitamin A. The controls had 104 (88.1\%) having received vitamin A while 14 (11.9\%) [N=118] did not receive vitamin A. A child who did not receive vitamin A was almost 10 times at risk of death (OR 9.57, 95\% CI [2.1043.70], $\mathrm{p}=0.012$ ). It must be mentioned that some of the cases died before six months when they were expected to have received vitamin A. Some controls however received vitamin A before they were six months old.

\section{Environment}

Almost all the homes in both study groups did not have any toilet facilities; 50(84.7\%) [N=59] for cases and $111(94.7 \%)[\mathrm{N}=118]$ for the controls. The predominant source of water in the district was the borehole; $41(69.5 \%)$ of cases and $67(56.8 \%)$ of controls used a bore-hole. Almost twice as many controls as cases; $15(12.7 \%)$ versus 4(6.8\%), had access to pipe-borne water. Only one household used what is regarded as a clean source of fuel (liquefied petroleum gas) and this was found in the home of a case. The environment was not found to have a significant influence on under-five mortality in the district.

The effect of other factors in addition to the ones mentioned above on under-five mortality is shown in Table 3 which is a summary of the results obtained after some of the possible risk factors for under-five mortality in the district were subjected to a conditional logistic regression.

\section{DISCUSSION}

The following were identified as determinants of under-five mortality in Builsa District: non- exclusive breastfeeding, non-vitamin A supplementation, non-use of insecticide-treated bednets (ITNs) and mothers with previous child deaths.

Factors that may have led to a decrease in underfive mortality in the district were the practice of exclusive breastfeeding (in more than $50 \%$ of cases for up to the recommended period of six months), vitamin A supplementation, the use of ITNs by children in the district and immunization. All these factors have been listed among the group of interventions that have been proven in various studies to enhance child survival and reduce under-five mortality (Jones et al., 2003, Caleson et al., 2003; Victora et al., 2007). 
50 Osei-Kwakye et al.

Table 3: Selected risk factors for under-five mortality in Builsa district, Ghana

\begin{tabular}{|c|c|c|}
\hline Risk Factor & Odds Ratio (95\% CI) & p value \\
\hline Birth interval (subsequent) & $0.76(0.55-1.05)$ & 0.67 \\
\hline Birth order & $0.96(0.79-1.16)$ & 0.68 \\
\hline $\begin{array}{l}\text { Time complementary feeding was started (months) } \\
\text { Below seven months }\end{array}$ & $1.06(0.79-1.41)$ & 0.70 \\
\hline At seven months or more & $\begin{array}{l}1.22(0.81-1.23) \\
0.67(0.55-1.31)\end{array}$ & $\mathrm{Pt}=0.68$ \\
\hline Time child was put to breast after delivery & $0.87(0.50-1.53)$ & 0.64 \\
\hline Immediately & $1.34(0.91-2.62)$ & \\
\hline Less than 1 hour & $1.27(0.78-3.64)$ & \\
\hline Less than 24 hours & $0.91(0.41-1.23)$ & $\mathrm{Pt}=0.71$ \\
\hline More than 24 hours & $0.98(0.56-1.56)$ & \\
\hline \multicolumn{3}{|l|}{ Place of Birth } \\
\hline Home & 1.00 & - \\
\hline TBA & $0.27(0.07-1.55)$ & 0.14 \\
\hline Clinic & $0.14(0.02-1.21)$ & 0.07 \\
\hline Health Centre & $0.57(0.14-2.39)$ & 0.44 \\
\hline Hospital & $2.54(0.79-8.78)$ & 0.14 \\
\hline Vitamin A & $9.57(2.10-43.70)$ & 0.006 \\
\hline Received vitamin A & $0.51(0.42-0.87)$ & \\
\hline Did not receive vitamin A & $10.30(6.54-12.30)$ & \\
\hline Exclusive breastfeeding (months) & $0.72(0.56-0.92)$ & 0.008 \\
\hline $0-3$ & $0.66(0.58-0.87)$ & \\
\hline 4-6 & $0.71(0.47-0.98)$ & \\
\hline$>6$ & $0.97(0.58-0.99)$ & \\
\hline Immunization & $0.57(0.43-0.77)$ & $<0.001$ \\
\hline ANC attendance & $0.94(0.7-1.18)$ & 0.61 \\
\hline None & $0.98(0.88-1.67)$ & $\mathrm{Pt}=0.79$ \\
\hline 1-4 times & $1.64(0.71-3.51)$ & \\
\hline$>4$ times & $0.76(0.77-3.3)$ & \\
\hline Mother's age at birth of child (years) & $0.97(0.91-1.05)$ & 0.52 \\
\hline $16-19$ & $0.67(0.88-2.61)$ & \\
\hline $20-29$ & $0.71(0.72-1.23)$ & $\mathrm{Pt}=0.66$ \\
\hline $30-39$ & $1.24(0.98-3.22)$ & \\
\hline $40-49$ & $0.98(0.77-1.31)$ & \\
\hline Parity & $1.03(0.85-1.26)$ & 0.74 \\
\hline No. of children alive & $0.54(0.40-0.73)$ & $<0.001$ \\
\hline None & $1.40(1.23-4.30)$ & \\
\hline $1-3$ & $1.21(1.11-1.23)$ & \\
\hline $4-6$ & $0.98(0.77-0.99)$ & \\
\hline $7+$ & $0.92(0.73-0.97)$ & \\
\hline No. of dead children & $7.45(3.63-15.46)$ & $<0.001$ \\
\hline None & $2.31(1.67-3.33)$ & \\
\hline 1 & $6.67(5.21-8.71)$ & $P t=0.006$ \\
\hline 2 & $6.63(4.32-7.71)$ & \\
\hline $3+$ & $7.81(3.21-12.80)$ & \\
\hline Sleeping under ITN & $0.12(0.04-0.34)$ & $<0.001$ \\
\hline Death of father & $2.00(0.40-9.90)$ & 0.52 \\
\hline \multicolumn{3}{|l|}{ Mother's educational level } \\
\hline None(Illiterate) & $1.15(0.23-1.50)$ & 0.71 \\
\hline Primary & $0.58(0.23-1.50)$ & 0.26 \\
\hline Middle/JSS & $0.89(0.25-3.14)$ & 0.85 \\
\hline SSS+ & $3.78(0.68-20.93)$ & 0.13 \\
\hline \multicolumn{3}{|l|}{ Income level } \\
\hline Mother & $1.00(1.00-1.00)$ & 0.35 \\
\hline Household & $1.00(1.00-1.00)$ & 0.33 \\
\hline \multicolumn{3}{|l|}{ Type of Cooking fuel } \\
\hline Firewood & $1.00(0.18-5.62)$ & 1.00 \\
\hline Charcoal & $1.46(0.70-3.02)$ & 0.31 \\
\hline Distance to nearest health facility & $0.72(0.52-1.00)$ & 0.049 \\
\hline
\end{tabular}

$P=$ overall $p$ value and $P t=p$ value for trend

Journal of Science and Technology @ KNUST April 2010 
The study confirmed the protective effect of exclusive breastfeeding in relation to under-five mortality as published in other studies. Exclusive breastfeeding has been identified in various studies as protecting infants especially in the first few months of life from ARI and diarrhoea (Cesar et al., 1999; Arifeen et al., 2001; Betran et al.; 2001; Mathres et al., 2001). This is important for child survival given the poverty levels of the district (and also the region) and the fact that breastmilk is readily available and at no cost to the mother.

The importance of vitamin A as a protective factor for under-five mortality was also confirmed by this study which showed that children who did not receive vitamin A were more than 10 times at risk of mortality. Giving vitamin A supplement to newborns has been shown to have a marked positive impact on early infant morbidity, mortality, growth and development (Rahmathullah et al., 2003; Grotto et al., 2003; Adu-Afarwuah et al., 2007; Haws et al., 2007; Klemm et al., 2007).

The proportion of mothers who owned an ITN $(96.1 \%)$ is far higher than the $32.2 \%$ quoted for Upper East region in the GDHS 2003 (GSS/ NMIMR/ORC Macro, 2004), which incidentally was the highest nationwide. This is also in sharp contrast to the median value of $13 \%$ (range: 1.1 $54 \%$ ) ownership of ITNs reported in a survey across some African countries (ORC Macro Inc. $(1998$ - 2001). This high figure could be attributed to the fact that in the district, pregnant women are given ITNs at a highly subsidized price both before and after delivery through a UNICEF-Ghana sponsored initiative. Additionally, the percentage of children in the study who were reported to have slept under an ITN the night before the survey (88.1\%) is far higher than that recoded for Upper East region - 22.7\% ( the region had the highest use of ITNs by children under-five nationwide according to the GDHS 2003) [GSS/NMIMR/ORC Macro., 2004]. Most of the mothers in the study reported that they used the nets together with their children. The study found a statistically significant difference between cases and controls regarding the use of ITNs (OR 0.11, 95\% CI [0.04-0.34], $\mathrm{p}<0.01$ ) and this confirms the beneficial effect of ITNs as reported in other studies (WHO/UNICEF, 2003).

Children of mothers who had had previous child deaths were about 8 times at risk of death (OR 7.50, 95\% CI [3.63-15.46], p<0.01) which is similar to findings from studies in Nepal (Katz et al., 2003) and Tanzania (Mturi and Curtis, 1995). The other significant finding regarding the influence of maternal factors on under-five mortality was that the more children a mother had alive, the less likely her children were to die (OR 0.54, 95\% CI [0.40-0.73], $\mathrm{p}<=0.01)$.

The beneficial effect of vaccinations on underfive mortality as published in some studies (Kristensen et al, 2000; Kabir et al, 2003) was also confirmed in this study. Immunization was a significant protective risk factor in relation to under-five mortality in the district, indicating the successful implementation of the Expanded Programme on Immunization (EPI), as part of child survival programmes in the district. District-wide implementation of immunization and vitamin A supplementation in children had an immense protective effect on child survival. However, these gains have to be sustained through improved information, education and communication (IE\&C) to mothers. Maternal education and support (provision of good water supply, sanitation and health care) for child health is essential in reducing childhood deaths in Builsa district.

\section{CONCLUSIONS AND RECOMMENDA- TIONS}

The study findings support the effectiveness of current child survival and development programmes in Builsa District, especially with immunizations and vitamin A supplementation. Such interventions need to be properly recorded in the child's Road to Health Chart (RTHC) to facilitate programme monitoring and evaluation. All health staff responsible for health programmes should be trained to identify and to pay special attention to mothers with previous child deaths in order to educate and assist them to prevent further childhood deaths.

Even in the midst of poverty, with a minimum of resources it is possible to achieve a lot in terms of improving the health status of commu- 


\section{Osei-Kwakye et al.}

nities. However such achievements require collaboration between government and the private sector especially non-governmental organizations (NGOs), to support local health authorities with the needed logistics to effectively implement their health programmes.

\section{ACKNOWLEDGEMENTS}

We will like to acknowledge the assistance of the following persons during the study: the chiefs and people of the Builsa District, the District Director of Health Services, Builsa District Dr. Thomas Mensah Afful, the Medical Superintendent, Builsa District Hospital - Dr. K. Sarkodie, the staff of the Builsa District Health Management Team as well as all health staff and community-based volunteers in the subdistricts.

\section{REFERENCES}

Adu-Afarwuah, S., Lartey, A., Briend, A, Zlotkin, S., Brown, K.H. and Dewey, K.G. (2007) Randomized comparison of 3 types of micronutrient supplements for home fortification of complementary foods in Ghana: Effects on growth and motor development. Am J Clin Nutr;86:412-420

Arifeen, S., Black, R.E., Antelman, G., Baqui, A., Caulfield, L. and Becker, S. (2001). Exclusive breastfeeding reduces Acute Respiratory Infection and Diarrhoea deaths among infants in Dhaka Slums. Paediatrics; 108: e67

Betran, A.P., de Onis, M., Lauer, J.A. and Villar, J. (2001). Ecological study of effect of breastfeeding on infant mortality in Latin America. BMJ; 323-303

Black, R.E., Morris, S.S. and Bryce, J. (2003). Where and why are 10 million children dying every year? Lancet 361: 2226-2234

Bryce, J., Arifeen, S., Pariyo, G., Lanata, C., Gwatkin, D., Habicht, J.P. and the MultiCountry Evaluation of IMCI Study Group (2003). Reducing child mortality: can public health deliver? Lancet 362: 159-164

Bryce, J., Requejo, J. and the Countdown
Working Group (2008). Tracking progress in maternal, neonatal and child survival: the 2008 report Available at www. countdown 2015mnch.org Accessed on 26/04/08

Bryce, J., Boschi-Pinto, C., Shibuya, K., Black, R.E. (2005). WHO estimates of the causes of death in children WHO Child Health Epidemiology Reference Group. . Lancet 365: 1147-1152.

Cesar, J.A., Victora, C.G., Barros, F.C., Santos I.S. and Flores, J.A. (1999). Impact of breastfeeding on admission for pneumonia during postneonatal period in Brazil: nested case control study. BMJ 318: 13161320.

Claeson, M., Gillespie, D., Mashinda, H., Troedsson, H., Victora, C.G. and the Bellagio Study Group on Child Survival (2003). Knowledge into action for child survival. Lancet 362: 323-327

Countdown Coverage Writing Group (2008). Countdown to 2015 for maternal, neonatal and child survival: the 2008 report on tracking coverage of interventions. Lancet 371: $1247-1258$

Ghana Health Service/Builsa District Health Management Team (2004). Annual Report. Sandema. Ghana

Ghana Statistical Service (GSS), Noguchi Memorial Institute for Medical Research (NMIMR) and ORC Macro. (2004). Ghana Demographic and Health Survey 2003. Calverton, Maryland. USA.

Ghana Statistical Service (GSS), Ghana Health Service (GHS) and ORC Macro (2009). Ghana Demographic and Health Survey 2008; Preliminary results. Calverton, Maryland. USA

Government of Ghana (2003). Ghana Poverty Reduction Strategy; An Agenda for Growth and Prosperity. Accra. Ghana

Grotto, I. Mimouni, M., Gdalevich, M. and Mimouni, D. (2003). Vitamin A supplementation and childhood morbidity from diarrhoea and respiratory infections: a meta -analysis. J Pediatr; 142: 297-304. 
Haws, R.A., Thomas, A.L., Bhutta, Z.A. and Darmstadt, G.L. (2007). Impact of packaged interventions on neonatal health: a review of the evidence. Health Policy Plan; 22: 193-215

Jones, G., Skeketee, R.W., Black, R.E., Bhutta, Z.A., Morris, S.S. and the Bellagio Child Survival Group (2003). How many child deaths can we prevent this year? Lancet; 362: 65-71.

Kabir, Z., Long, J., Reddaiah, V.P., Kevany, J. and Kapoor, S.K. (2003). Non specific effect of measles on overall child mortality in an area of rural India with high vaccination coverage: a population based case control study. Bulletin of the World Health Organization; 81(4):244-50.

Katz, J., West, Jr., K.P., Subarna, K.K., Christian, P., LeClerq, S.C., Pradhan, E.K. and Shrestha S.R. (2003). Risk factors for early infant mortality in Sarlahi district, Nepal. Bulletin of the World Health Organization; 81:717-725.

Klemm, R., Labrique, A. and Christian, P. (2007). Efficacy of newborn vitamin A supplementation in reducing infant mortality in rural Bangladesh: the JiVitA-2 trial. In: Proceedings of the Micronutrient Forum. Consequences and control of micronutrient deficiencies: science, policy and programs-defining the issues. Istanbul, Turkey. April 16-18, 2007

Kristensen, L., Aaby, P., Jensen, H. (2000). Routine vaccinations and child survival: A follow up study in Guinea Bissau, West Africa. BMJ; 321: 1435-9.

Mathres, C.D., Murray, C.J.L., Lopez, A.D. and Stein, C. (2001). The global burden of disease 2000 project: objectives, methods, data sources and preliminary results.

Mosley, W.H. and Chen, L. (1984). An analytical framework for the study of child survival in developing countries. In Mosley WH and Chen L (eds) Child Survival:

Strategies for Research. Population and Development review, Supplement to Volume 10:
$25-45$.

Mturi, A.J. and Curtis, S.L. (1995). The determinants of infant and child mortality in Tanzania. Health Policy Planning; 10(4): 384-94.

ORC Macro., Demographic and Health Surveys (DHS) (1998-2001), Calverton, MD, Available at:http://www.measure dhs.com Accessed on 10/04/05

Rahmathullah, L., Tielsch, J.M., Thulasiraj, R.D., Katz, J., Coles, C., Devi, S., Rajeesh, J., Prakhash, K., Sadanand, A.V., Edwin, N. and Kamraj, C. (2003). Impact of Supplementing newborn infants with vitamin A on early infant mortality: community based randomized trial in southern India. BMJ; 327:254.

United Nations (2000). The Millennium Development Goals. UN, New York. NY. USA

UNICEF (2008). The state of the world's children. UNICEF, New York. NY. USA.

UNICEF (2004). The state of the world's children. UNICEF, New York. NY. USA. Available at http://www.unicef.org Accessed on $10 / 09 / 07$

UNICEF (2008) The state of Africa's children 2008. UNICEF, New York, NY Available at http://www.unicef.org Accessed on $10 / 06 / 08$

Victora, C.G., Bryce, J. and Black, R.E. (2007). Learning from new initiatives in maternal and child health. Lancet 370: 1113-14.

WHO/UNICEF (2003). The Africa Malaria Report WHO/CDS/MAL/2003.1093.

WHO (2000). Nutrition for Health and Development (NHD). Sustainable Development and Healthy Environments (SDE): Turning the tide of Malnutrition. Responding to the challenge of the 21 st century (document WHO/NHD/00.7).

WHO (2007). World Health Statistics. Geneva. Switzerland

WHO/IVR (2003). State of the art of new vaccines, Research and Development. WHO, Geneva. Switzerland 